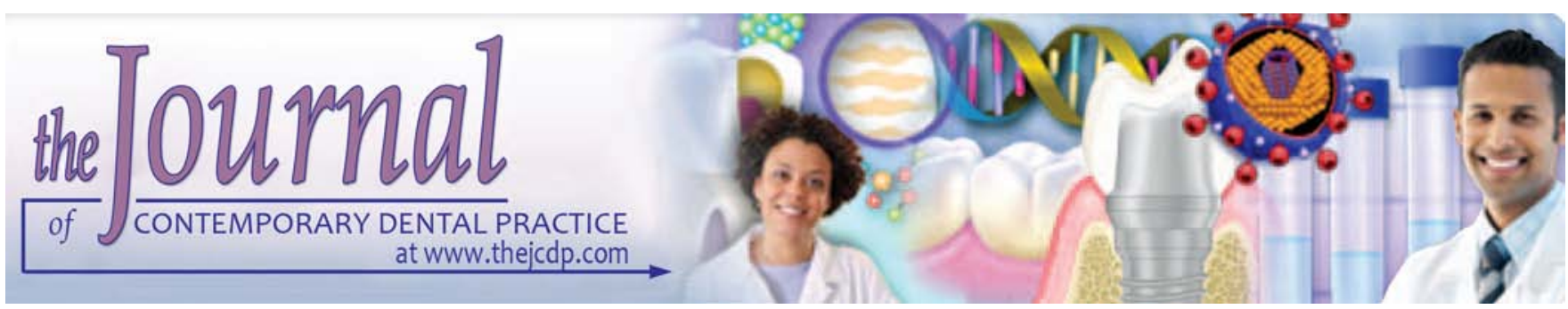

\title{
Effect of Three-wall Bony Defect along Various Root Surfaces on Position of Center of Resistance: A 3D Finite Element Analysis
}

${ }^{1}$ Achint Devendra Chachada, ${ }^{2}$ PV Hazarey, ${ }^{3}$ Mrunal Shyam Aley, ${ }^{4}$ Harish Keshaorao Atram, ${ }^{5}$ Asmita Kharche

\begin{abstract}
Introduction: Increase in adult orthodontic patients has increased the challenges faced by orthodontists, as they often present themselves with a varying degree of dental and periodontal compromise, in which the entire orthodontic treatment planning will revolve around maintenance and augmentation of supporting apparatus. One of the many factors to be considered during treating an adult patient is the height of alveolar bone and its effect on center of resistance (CRes).
\end{abstract}

Materials and methods: Eight 3D analytical models of upper central incisor were designed using 'Solid Works Office Premium'. The models were subjected to 3 and $6 \mathrm{~mm}$ bone loss along all four surfaces, i.e. labial, lingual, mesial and distal. One Newton of retraction force was applied on labial surface of tooth on model number 1, 2, 5 and 6 and $1 \mathrm{~N}$ of distalization force was applied to model number $3,4,7$ and 8 . The relative location of the CRes to the total root length was taken as $41.8 \%$ of total root length from the root apex. The ANSYS software was used to evaluate the change in CRes on all the models.

Results: It was observed that CRes shifted apically from its relative location (41.8\% from apex); however, this shift was clinically insignificant. Minimum deflection of CRes, $0.0122 \mathrm{~mm}$, was seen when a distalization force was applied on model with $6 \mathrm{~mm}$ bone loss on distal surface, while maximum deflection of $0.0245 \mathrm{~mm}$ was seen when retraction force was applied on model with $6 \mathrm{~mm}$ bone loss on labial surface.

Conclusion: The resultant displacement in position of center of resistance is negligible; hence, there is no need of changing biomechanics during orthodontic treatment for a tooth with three

\footnotetext{
${ }^{1-5}$ Department of Orthodontics and Dentofacial Orthopedics Swargiya Dadasaheb Kalmegh Smruti Dental College and Hospital, Nagpur, Maharashtra, India

Corresponding Author: Achint Devendra Chachada, Reader Department of Orthodontics and Dentofacial Orthopedics Swargiya Dadasaheb Kalmegh Smruti Dental College and Hospital, Nagpur, Maharashtra, India, Phone: +919371598765 e-mail: achint.chachada@gmail.com
}

wall infrabony defects. However, it is necessary to further study other infrabony defects like two wall or one wall defect, and their effect on position of CRes.

Keywords: Alveolar bone loss, Asymmetric bone loss, Center of resistance, Central incisor finite element study.

How to cite this article: Chachada AD, Hazarey PV, Aley MS, Atram HK, Kharche A. Effect of Three-wall Bony Defect along Various Root Surfaces on Position of Center of Resistance: A 3D Finite Element Analysis. J Contemp Dent Pract 2015;16(8): 688-691.

Source of support: Nil

Conflict of interest: None

\section{INTRODUCTION}

Adults are seeking orthodontic treatment at historic levels, according a survey from the American Association of Orthodontists (AAO). The number of adult patients increased $14 \%$ in a 2-year period from 2010 to 2012, to a record high of $1,225,850$ patients aged 18 or more. ${ }^{1,2}$ Increase in adult orthodontic patient has increased the challenges faced by orthodontists, as these patients often present themselves with a varying degree of dental and periodontal compromise that may range from marginal, without any significant effect on the prognosis, to severe, in which case the entire orthodontic treatment planning will revolve around maintenance and augmentation of supporting apparatus. One of the many factors to be considered during treating an adult patient is the height of the alveolar bone.

Previous literature provides us the knowledge about change in position of center of resistance (CRes) for varying heights of alveolar bone. ${ }^{3,4}$ All these studies show that as the height of alveolar bone decreases, CRes shifts. This shift needs increase in moment-to-force ratio for translating a tooth. 
All the research conducted in this area has considered equal amount of bone loss on all surfaces of root. None has considered what effect different types of infrabony defects have on position of center of resistance, wherein alveolar bone height is different on different root surfaces. In periodontally compromised patients, bone loss is not always similar on all the sides. According to Goldman and Cohen, there are three types of infrabony defects: one wall, two wall and three wall infrabony defects. ${ }^{5}$ Hence, it is necessary to know the change in CRes for cases with infrabony defects for better application of biomechanics. This study was carried out to evaluate the change in position of CRes for tooth with three wall infrabony defect with following aims and objectives:

- To evaluate the change in position of CRes due to bone loss on labial and lingual surface, when tooth is subjected to $1 \mathrm{~N}$ of retraction force.

- To evaluate the change in position of CRes due to bone loss on mesial and distal surface, when tooth is subjected to $1 \mathrm{~N}$ of distalization force.

\section{MATERIALS AND METHODS}

Eight 3D analytical models of upper central incisor were designed using 'Solid Works Office Premium'. Models were designed as per the dimensions and morphology in Wheeler's dental anatomy, physiology and occlusion text book. Each model consisted of a tooth, periodontal ligament and both cortical and cancellous bone. Variations in the thickness of periodontal ligament (PDL) in different layers of tooth were designed according to Coolidge model (Table 1$).{ }^{6}$ Physical properties of different materials were selected from previous studies (Table 2). ${ }^{7-9}$

Table 1: Geometry of the PDM widths in the 3D model according to Coolidge ${ }^{6}$

\begin{tabular}{lllll}
\hline $\begin{array}{l}\text { Distance from the } \\
\text { alveolar crest }(\mathrm{mm})\end{array}$ & $\begin{array}{l}\text { Distal } \\
(\mathrm{mm})\end{array}$ & $\begin{array}{l}\text { Lingual } \\
(\mathrm{mm})\end{array}$ & $\begin{array}{l}\text { Mesial } \\
(\mathrm{mm})\end{array}$ & $\begin{array}{l}\text { Labial } \\
(\mathrm{mm})\end{array}$ \\
\hline 13.0 & 0.25 & 0.25 & 0.22 & 0.25 \\
10.5 & 0.18 & 0.22 & 0.20 & 0.22 \\
8.0 & 0.15 & 0.20 & 0.17 & 0.26 \\
6.5 & 0.14 & 0.18 & 0.16 & 0.18 \\
5.0 & 0.15 & 0.20 & 0.17 & 0.26 \\
2.5 & 0.18 & 0.22 & 0.20 & 0.22 \\
0 & 0.19 & 0.24 & 0.21 & 0.24 \\
\hline
\end{tabular}

Table 2: Mechanical properties for the structural elements

\begin{tabular}{lll}
\hline Material & Young's modulus $\left(\mathrm{N} / \mathrm{mm}^{2}\right)$ & Poisson's ratio \\
\hline Tooth & 20300 & 0.30 \\
PDM & 0.667 & 0.49 \\
Cancellous bone & 13700 & 0.38 \\
Cortical bone & 34000 & 0.26 \\
\hline
\end{tabular}

The models were subjected to 3 and $6 \mathrm{~mm}$ bone loss along all four surfaces (Figs 1 to 4 ) as follows:

- Model 1: $3 \mathrm{~mm}$ bone loss on labial surface (Fig. 1)

- Model 2: $3 \mathrm{~mm}$ bone loss on lingual surface (Fig. 1)

- Model 3: $3 \mathrm{~mm}$ bone loss on mesial surface (Fig. 2)

- Model 4: $3 \mathrm{~mm}$ bone loss on distal surface (Fig. 2)

- Model 5: $6 \mathrm{~mm}$ bone loss on labial surface (Fig. 3)

- Model 6: $6 \mathrm{~mm}$ bone loss on lingual surface (Fig. 3)

- Model 7: $6 \mathrm{~mm}$ bone loss on mesial surface (Fig. 4)

- Model 8: $6 \mathrm{~mm}$ bone loss on distal surface (Fig. 4)

A $1 \mathrm{~N}$ of retraction force was applied on labial surface of tooth on model number 1, 2, 5 and 6 with point of force application centered mesiodistally (this was presumed to be the location of the brackets). The force applied was tipping in nature and perpendicular to long axis of the tooth. Similarly, $1 \mathrm{~N}$ of distalization force was applied to model number 3, 4, 7 and 8 . The relative location of the CRes to the total root length was taken as $41.8 \%$ of total root length from the root apex. The ANSYS software was used to evaluate the change in CRes on all the models.

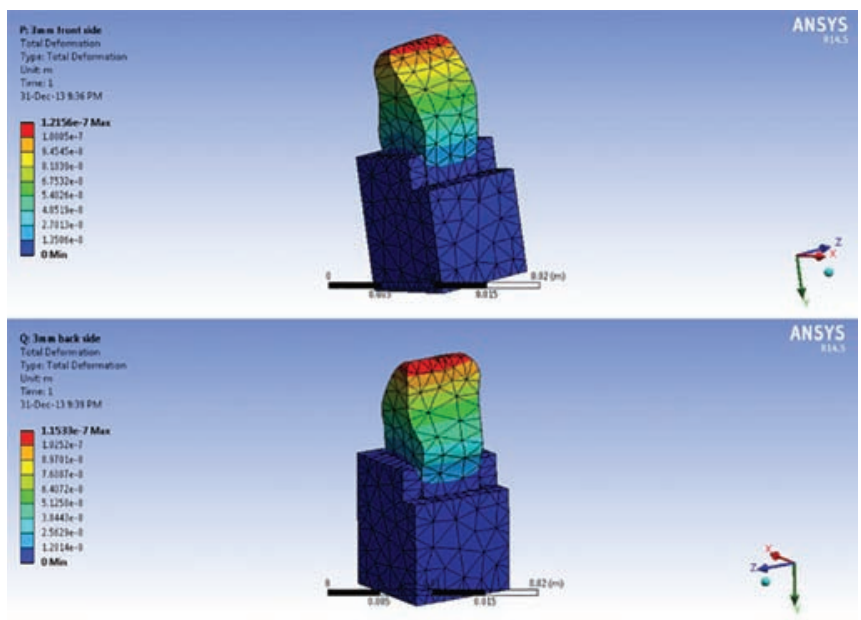

Fig. 1: Tooth model with $3 \mathrm{~mm}$ bone loss on labial and lingual surfaces

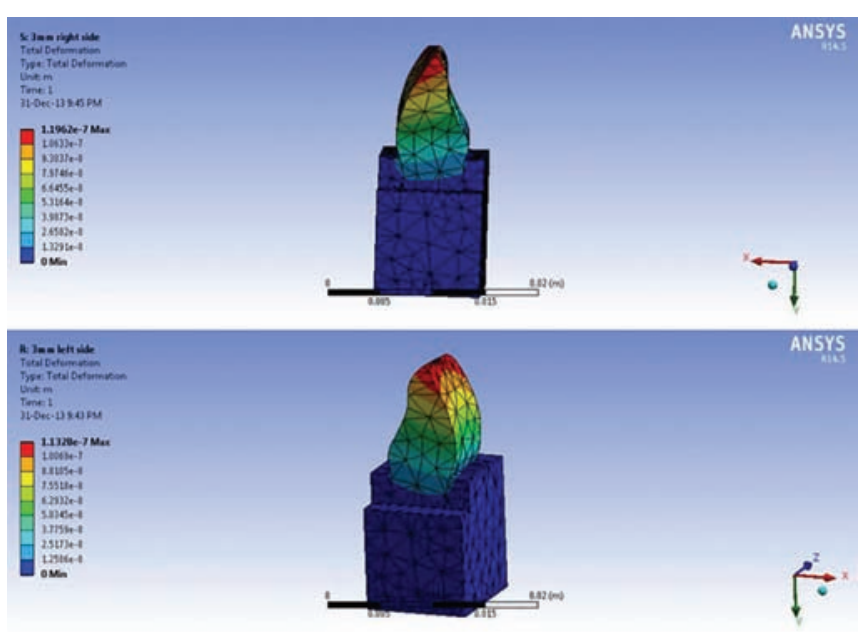

Fig. 2: Tooth model with $3 \mathrm{~mm}$ bone loss on mesial and distal surfaces 


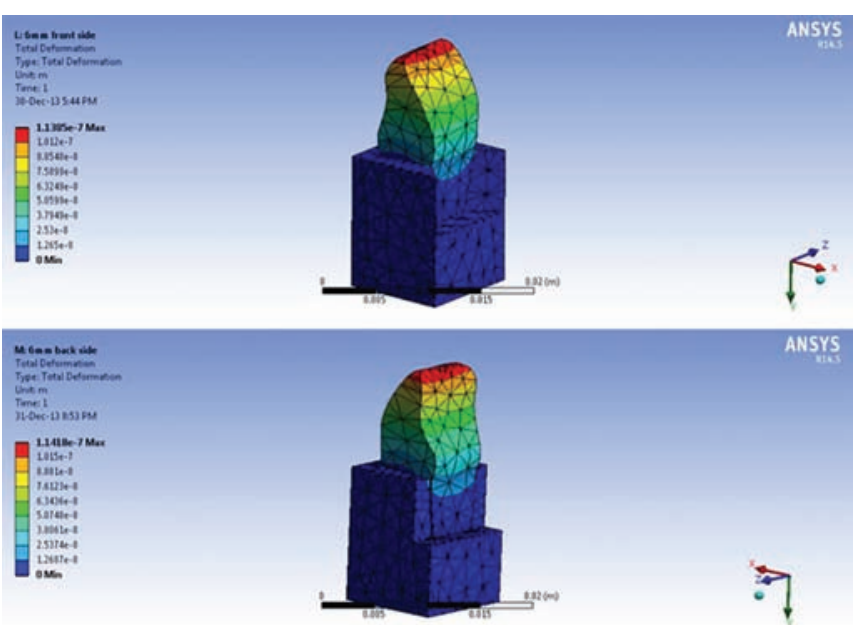

Fig. 3: Tooth model with $6 \mathrm{~mm}$ bone loss on labial and lingual surfaces

\section{RESULTS AND OBSERVATIONS}

On evaluation, it was observed that CRes shifted apically from its relative location ( $41.8 \%$ from apex). The resultant displacement of CRes is mentioned in Table 3.

Minimum deflection of CRes, $0.0122 \mathrm{~mm}$, was seen when a distalization force was applied on model with $6 \mathrm{~mm}$ bone loss on distal surface; while maximum deflection of $0.0245 \mathrm{~mm}$ was seen when retraction force was applied on model with $6 \mathrm{~mm}$ bone loss on labial surface.

\section{DISCUSSION}

Clinical studies report a slight loss of periodontal attachment in adults during treatment with fixed orthodontic appliances. It is necessary for us to know what effect loss of periodontal attachment has on biomechanics so as to achieve tipping, bodily or root movement. Change in CRes requires change in moment-to-force $(M / F)$ ratio to achieve same amount of bodily movement for a given

Table 3: Resultant apical displacement of CRes from relative its relative position ( $41.8 \%$ from root apex) in eight tooth models

\begin{tabular}{ll}
\hline Tooth model & $\begin{array}{l}\text { Resultant displacement } \\
(\mathrm{mm})\end{array}$ \\
\hline $\begin{array}{l}\text { Tooth model with } 3 \mathrm{~mm} \text { bone } \\
\text { loss on labial surface }\end{array}$ & 0.016 \\
$\begin{array}{l}\text { Tooth model with } 3 \mathrm{~mm} \text { bone } \\
\text { loss on lingual surface }\end{array}$ & 0.014 \\
$\begin{array}{l}\text { Tooth model with } 3 \mathrm{~mm} \text { bone } \\
\text { loss on mesial surface }\end{array}$ & 0.015 \\
$\begin{array}{l}\text { Tooth model with } 3 \mathrm{~mm} \text { bone } \\
\text { loss on distal surface }\end{array}$ & 0.018 \\
$\begin{array}{l}\text { Tooth model with } 6 \mathrm{~mm} \text { bone } \\
\text { loss on labial surface }\end{array}$ & 0.024 \\
$\begin{array}{l}\text { Tooth model with } 6 \mathrm{~mm} \text { bone } \\
\text { loss on lingual surface }\end{array}$ & 0.015 \\
$\begin{array}{l}\text { Tooth model with } 6 \mathrm{~mm} \text { bone } \\
\text { loss on mesial surface }\end{array}$ & 0.018 \\
$\begin{array}{l}\text { Tooth model with } 6 \mathrm{~mm} \text { bone } \\
\text { loss on distal surface }\end{array}$ & 0.012 \\
\hline
\end{tabular}
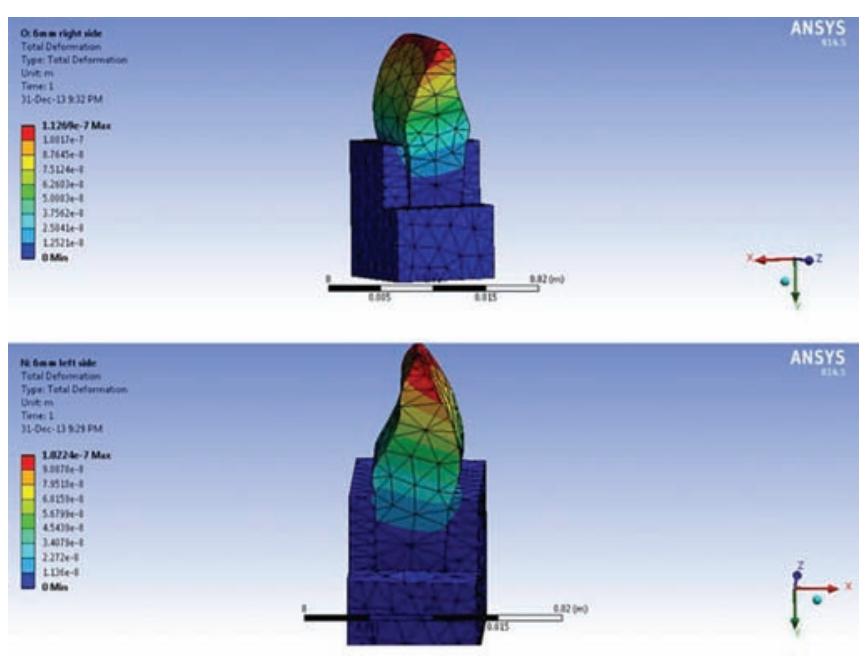

Fig. 4: Tooth model with $6 \mathrm{~mm}$ bone loss on mesial and distal surfaces

tooth. Bantleon states that $3 \mathrm{~mm}$ of alveolar bone loss causes $20 \%$ of $\mathrm{M} / \mathrm{F}$ ratio increment to maintain bodily movement, while Geramy found that $17.35 \%$ of $\mathrm{M} / \mathrm{F}$ ratio increment was required for same amount of bone loss. 3,10 Tanne et al studied the effect of alveolar bone loss on the $\mathrm{M} / \mathrm{F}$ ratio for bodily movement of a maxillary central incisor with $13.0 \mathrm{~mm}$ root length, with the use of a 3D finite element model. ${ }^{4}$ According to their results, the M/F ratio increased from 10.7 (no bone loss) to 12.3, 13.9, and 15.0 for $2.5,5.0$, and $6.5 \mathrm{~mm}$ alveolar bone loss, respectively. Jagdev et al studied the amount of tooth displacement and stress distribution with varying degree of alveolar bone loss. ${ }^{11}$ They concluded that stresses progressively increased in magnitude with decrease in alveolar bone height; also, it was observed in their study that there was overall increase in the amount of tooth displacement with decrease in alveolar bone height.

Until now, all the researchers have focused on even or circumferential type of bone loss for evaluation of change in position of center of resistance. In this study, asymmetrical bone loss (three wall bony defect) was studied to evaluate the change in position of the CRes. Orthodontic treatment requires buccolingual as well as mesiodistal tooth movement. Hence, in this study effect of bone loss on position of CRes during mesiodistal tooth movement was also taken into consideration. The present study shows that when there is attachment loss on only one tooth surface, i.e. labial, lingual, mesial or distal, the CRes shifts apically. However, the amount of deflection, even when the bone loss was $6 \mathrm{~mm}$, is clinically insignificant, i.e. in situations where bone loss is present only on one surface of tooth and other surfaces are intact, there is no need to change biomechanics.

Limitation of this study is same as for any finite element study. The other two bony defects also need to be studied to see the effect of asymmetric bone loss on 
change in position of CRes. With advent of 3D finite element models, the 3D location of CRes is possible. Viecilli et al showed that the 3D axes of resistance, or their 2D projection intersections, should be used to plan movement of an arbitrary tooth. ${ }^{12}$ Clinical approximations to a small 3D 'center of resistance volume' might be adequate in nearly symmetric periodontal ligament cases. Dathe et al concluded from their study that the center of resistance should be replaced by a newer and wider mathematical concept, the 'center of elasticity', together with a limiting parameter, the 'radius of resistance' ${ }^{13}$

\section{CONCLUSION}

It was concluded from the results of the present study that there is negligible deflection of CRes when alveolar bone loss is only on one surface of tooth. Maximum deflection of $0.0245 \mathrm{~mm}$ was seen when retraction force was applied on model with $6 \mathrm{~mm}$ bone loss on labial surface which is clinically insignificant.

\section{CLINICAL IMPLICATIONS}

Since the resultant displacement in position of center of resistance is negligible, there is no need of changing biomechanics during orthodontic treatment for a tooth with three wall infrabony defects. However, it is necessary to further study other infrabony defects like two-wall or one wall defect, and their effect on position of CRes, as this article covers only three-wall infrabony defect.

\section{REFERENCES}

1. Scott $P$, Fleming P, DiBiase A. An update in adult orthodontics. Dent Update 2007;34(7):427-428.
2. American Association of Orthodontists [Internet]. 'The Economics of Orthodontics' survey-smiles are in style. Available at http://www1.mylifemysmile.org/sites / default/files/Results $\% 20$ of $\% 202012 \% 20$ AAO $\% 20$ Patient $\% 20$ Census\%20Survey_0.pdf

3. Geramy A. Alveolar bone resorption and the center of resistance modification (3-D analysis by means of the finite element method). Am J Orthod Dentofacial Orthop 2000;117(4): 399-405.

4. Tanne K, Nagataki T, Inoue Y, Sakuda M, Burstone CJ. Patterns of initial tooth displacements associated with various root lengths and alveolar bone heights. Am J Orthod Dentofacial Orthop 1991;100(1):66-71.

5. Goldman HA, Cohen DW. The infrabony pocket: Classification and treatment. J Periodontol 1958;29(4):272-291.

6. Coolidge ED. The thickness of the human periodontal membrane. J Am Dent Assoc Dent Cosmos 1937;24(8):1960-1970.

7. Tanne K, Koenig HA, Burstone CJ. Moment to force ratios and the center of rotation. Am J Orthod Dentofacial Orthop 1988;94(5):426-431.

8. McGuinness NJP, Wilson AN, Jones ML, Middleton J. A stress analysis of the periodontal ligament under various orthodontic loadings. Eur J Orthod 1991;13(3):231-242.

9. Tanne K, Sakuda M, Burstone CJ. Three-dimensional finite element analysis for stress in the periodontal tissue by orthodontic forces. Am J Orthod 1987;92(6):499-505.

10. Bantelon HP. Biomechanics in clinical orthodontics. Modified lingual lever arm technique: biomechanical considerations; Philadelphia: WB Saunders; 1997. p. 229-245.

11. Jagdev PS, Mehrotra P, Dattada H, Rastogi N. Evaluation of stress on tooth and periodontium with varying degree of bone support on orthodontic force application: A 3D finite element analysis. J Ind Orthod Soc 2009;43(2):3-14.

12. Viecilli RF, Budiman A, Burstone CJ. Axes of resistance for tooth movement: does the center of resistance exist in 3-Dimensional space? Am J Orthod Dentofacial Orthop 2013; 143(2):163-172.

13. DatheH,NägerlH,Kubein-Meesenburg D. A caveat concerning center of resistance. J Dent Biomech 2013;4:1758736013499770. 